\title{
Novel Approaches to Inhibition of Gastric Acid Secretion
}

\author{
George Sachs • Jai Moo Shin • Richard Hunt
}

Published online: 6 October 2010

(C) The Author(s) 2010. This article is published with open access at Springerlink.com

\begin{abstract}
The gastric H,K-adenosine triphosphatase (ATPase) is the primary target for treatment of acidrelated diseases. Proton pump inhibitors (PPIs) are weak bases composed of two moieties, a substituted pyridine with a primary $\mathrm{pK}_{\mathrm{a}}$ of about 4.0 that allows selective accumulation in the secretory canaliculus of the parietal cell, and a benzimidazole with a second $\mathrm{pK}_{\mathrm{a}}$ of about 1.0. Protonation of this benzimidazole activates these prodrugs, converting them to sulfenic acids and/or sulfenamides that react covalently with one or more cysteines accessible from the luminal surface of the ATPase. The maximal pharmacodynamic effect of PPIs as a group relies on cyclic adenosine monophosphate-driven H,K-ATPase translocation from the cytoplasm to the canalicular membrane of the parietal cell. At present, this effect can only be achieved with protein meal stimulation. Because of covalent binding, inhibitory effects last much longer than their plasma halflife. However, the short dwell-time of the drug in the blood
\end{abstract}

G. Sachs $(\bowtie) \cdot$ J. M. Shin

Department of Physiology and Medicine, David Geffen School

of Medicine, University of California at Los Angeles,

and VA Greater Los Angeles Healthcare System,

Room 324, Building 113, 11301 Wilshire Boulevard,

Los Angeles, CA 90073, USA

e-mail: gsachs@ucla.edu

J. M. Shin

e-mail: jaishin@ucla.edu

R. Hunt

Farncombe Family Digestive Disease Research Institute, Division of Gastroenterology, McMaster University Health

Sciences Centre,

1200 Main Street West, Room 4W8A,

Hamilton, ON L8N 3Z5, Canada

e-mail: huntr@mcmaster.ca and the requirement for acid activation impair their efficacy in acid suppression, particularly at night. All PPIs give excellent healing of peptic ulcer and produce good, but less than satisfactory, results in reflux esophagitis. PPIs combined with antibiotics eradicate Helicobacter pylori, but success has fallen to less than $80 \%$. Longer dwell-time PPIs promise to improve acid suppression and hence clinical outcome. Potassium-competitive acid blockers (P-CABs) are another class of ATPase inhibitors, and at least one is in development. The P-CAB under development has a long duration of action even though its binding is not covalent. PPIs with a longer dwell time or P-CABs with long duration promise to address unmet clinical needs arising from an inability to inhibit nighttime acid secretion, with continued symptoms, delayed healing, and growth suppression of $H$. pylori reducing susceptibility to clarithromycin and amoxicillin. Thus, novel and more effective suppression of acid secretion would benefit those who suffer from acid-related morbidity, continuing esophageal damage and pain, nonsteroidal antiinflammatory drug-induced ulcers, and nonresponders to H. pylori eradication.

Keywords Proton pump inhibitor - Gastric H,K-ATPase . Ulcer. Gastroesophageal reflux disease

\section{Introduction}

The two major types of acid-related disorders are peptic ulcer disease (PUD) and gastroesophageal reflux disease (GERD), although other extra-esophageal disorders are ascribed to gastric acid reflux (eg, reflux laryngitis). The target for treatment was and still is reduction of gastric acidity. However, despite clinical and commercial success, histamine-2 receptor antagonists $\left(\mathrm{H}_{2}\right.$-RAs $)$ have several 
pharmacologic limitations that are increasingly apparent in the clinical setting. The $\mathrm{H}_{2}$-RAs are less effective for the management of GERD and gastrointestinal (GI) bleeding than for healing of PUD, and the rapid development of tachyphylaxis limits their usefulness for long-term maintenance treatment or high-dose intravenous use. The $\mathrm{H}_{2}$-RAs have been largely supplanted by the proton pump inhibitors (PPIs) because of greater efficacy and lack of pharmacologic tolerance. The PPIs were found to be very effective for the management of patients with erosive esophagitis, and a meta-analysis in 1997 confirmed their superiority to $\mathrm{H}_{2}$-RAs for the treatment of GERD, particularly erosive esophagitis [1].

PPIs have also found a place in treatment of a wide range of acid-related disorders, including nonerosive reflux disease (NERD) and PUD, especially as treatment or prophylaxis of GI injury caused by nonsteroidal antiinflammatory drugs (NSAID). PPIs have became established as combination antisecretory treatment, together with antibiotic therapy, for the eradication of Helicobacter pylori infection. Furthermore, PPIs have become the standard of care in patients with nonvariceal upper GI bleeding or for the prevention of stress-related mucosal bleeding in intensive care units.

\section{$\mathrm{H}_{2}$-Histamine Receptor Antagonists and PPIs}

The launch in 1979 of cimetidine (Tagamet; GlaxoSmithKline, Philadelphia, PA) revolutionized medical treatment of PUD and GERD, for the first time providing relatively long-lasting reduction of gastric acid secretion with healing of both gastric and duodenal ulcers and some remission of the symptoms of GERD. Cimetidine was followed by ranitidine (Zantac; Boehringer Ingelheim, Ingelheim, Germany), famotidine (Pepcid; Johnson \& Johnson, New Brunswick, NJ), and nizatidine (Axid; Eli Lilly Indianapolis, IN)-all of which have an identical mechanism of action, namely reversible inhibition of the histamine $\left(\mathrm{H}_{2}\right)$ receptor on the acid-secreting parietal cell of the stomach. These drugs have very similar mechanisms of action. Famotidine is the most potent commonly prescribed $\mathrm{H}_{2}-\mathrm{RA}$, with about a 20 -fold increase in potency. $\mathrm{H}_{2}$-RAs result in short-lived inhibition of acid secretion; the onset of inhibition occurs after about $4 \mathrm{~h}$ and maximal inhibition after about $8 \mathrm{~h}$, with return of acid secretion after about $12 \mathrm{~h}$, therefore requiring at least twicedaily administration. Moreover, all these drugs exhibit tolerance such that they lose about $50 \%$ of their efficacy over a 7-day period (Fig. 1).

Figure 1 shows the effect of ranitidine given at night to reduce nighttime GERD symptoms on days 1,7 , and 28 ; intragastric $\mathrm{pH}$ is raised to greater than 5.0 by nighttime of day 1 , but reaches a level between 2.0 and 3.0 by day 28 [2]. Hence, this class of drug offers little likelihood of

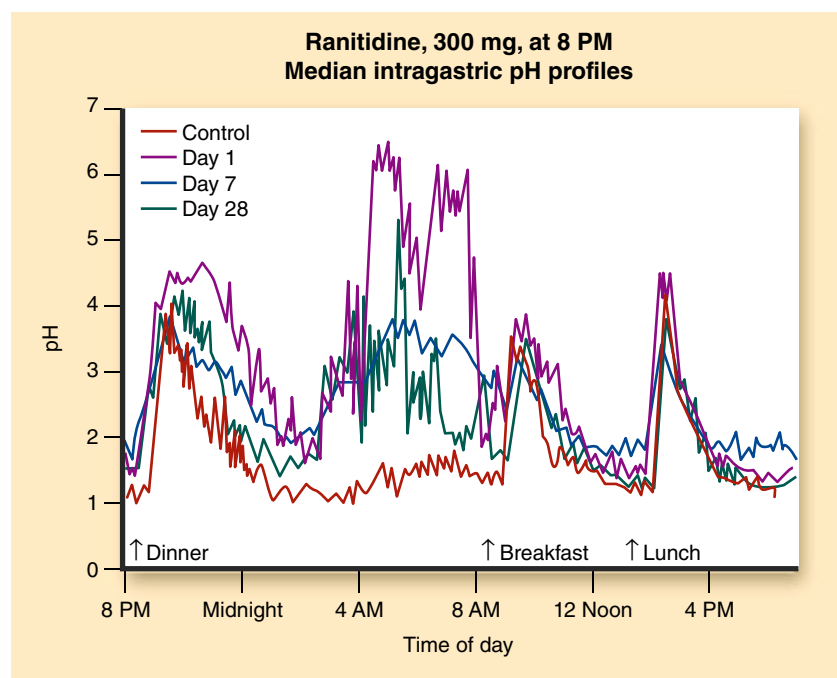

Fig. 1 The effect of nighttime administration of ranitidine, $300 \mathrm{mg}$, on intragastric $\mathrm{pH}$

improved GERD symptoms, because the tolerization to ranitidine shown in Figure 1 is shared by all $\mathrm{H}_{2}$-RAs.

The discovery that PUD was largely the result of infection with $H$. pylori revolutionized the treatment of PUD, namely eradication of the infection either with triple or quadruple therapy. Hence, $\mathrm{H}_{2}-\mathrm{RAs}$ are used to treat symptomatic GERD, but are not used alone for PUD. NSAID-induced PUD requires better acid inhibition for treatment, and hence $\mathrm{H}_{2}$-RAs are not indicated with concomitant NSAID use.

The synthesis of a novel secretory inhibitor, omeprazole (Prilosec; AstraZeneca, Wilmington, DE), in 1978 and its launch in 1989 in the United States further revolutionized treatment of acid-related diseases. Omeprazole was the first drug of the PPI class. Four more such PPIs are now on the market: lansoprazole (Prevacid; Takeda Pharmaceuticals, Osaka, Japan), pantoprazole (Protonix; Wyeth-Ayerst Laboratories, Madison, NJ), rabeprazole (Aciphex; Eisai, Tokyo, Japan), and esomeprazole (Nexium; AstraZeneca, Wilmington, DE). Their mechanism of action is unique and their target is the active gastric proton pump, the $\mathrm{H}$, K-ATPase. They are weak-base prodrugs and accumulate in the unique, highly acidic canalicular space of the active parietal cell, where the $\mathrm{pH}$ is less than 2.0. At this $\mathrm{pH}$, they are converted to the active form of the drug, which then covalently binds to one or more cysteines that are accessed from the luminal surface of the pump. Thus the inhibition is long-lasting and no tolerance has been observed with this class of drug. However, they require the presence of acid secretion for accumulation and activation, hence their action is meal-dependent. Moreover, they have a relatively short plasma half-life of about $2 \mathrm{~h}$. Given this mechanism of action, the effect on acid secretion is cumulative, increasing to steady state 
after 3 to 5 days of administration, because pumps that are nonsecreting will not be inhibited whereas inhibited pumps will stay inhibited. A typical intragastric $\mathrm{pH}$ profile is shown for pantoprazole in Fig. 2.

The ability to progressively increase intragastric $\mathrm{pH}$ with $\mathrm{H}_{2}$-RAs and PPIs resulted in a comprehensive metaanalysis of the relationship between intragastric $\mathrm{pH}$, healing of duodenal and gastric ulcers, and treatment of GERD immediately after the launch of omeprazole. This analysis predicted that a $\mathrm{pH}$ greater than 4.0 for $16 \mathrm{~h}$ per day was optimum for healing of GERD and a $\mathrm{pH}$ greater than 3.0 was optimum for healing of duodenal ulcers (Fig. 3).

The gastric H,K-ATPase has a half-life of $50 \mathrm{~h}$, hence about $25 \%$ of pumps are synthesized per day, at a rate of about $1 \%$ per hour [3]. It also seems likely that this synthesis has a circadian rhythm, with more pumps synthesized at night than during the day. Thus, in the morning, before breakfast, a theoretical maximal pool of parietal cell H,K-ATPase is available for activation. Figure 2 illustrates the persistence of nighttime acid secretion with PPI administration, most likely because of the presence of de novo synthesized pumps that were never exposed to the PPI.

One of the most recent PPIs to be approved by the Food and Drug Administration (FDA) is esomeprazole, the Senantiomer of the chiral omeprazole. Esomeprazole is viewed as the most effective PPI launched thus far. Its effect on intragastric $\mathrm{pH}$ and pharmacokinetic profile as compared to omeprazole, $20 \mathrm{mg}$, is shown in Fig. 4. Figure 4 shows that esomeprazole, $40 \mathrm{mg}$, results in greater elevation of intragastric $\mathrm{pH}$ and an increase in the plasma residence time, whereas virtually no difference can be seen between omeprazole, $20 \mathrm{mg}$, and esomeprazole, $20 \mathrm{mg}$.

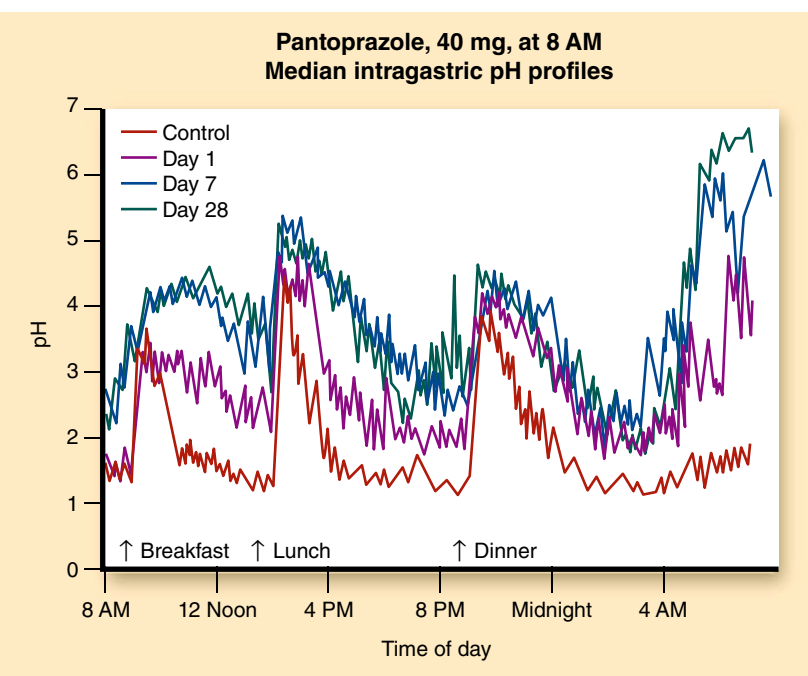

Fig. 2 The effect of morning administration of pantoprazole, $40 \mathrm{mg}$, on intragastric $\mathrm{pH}$

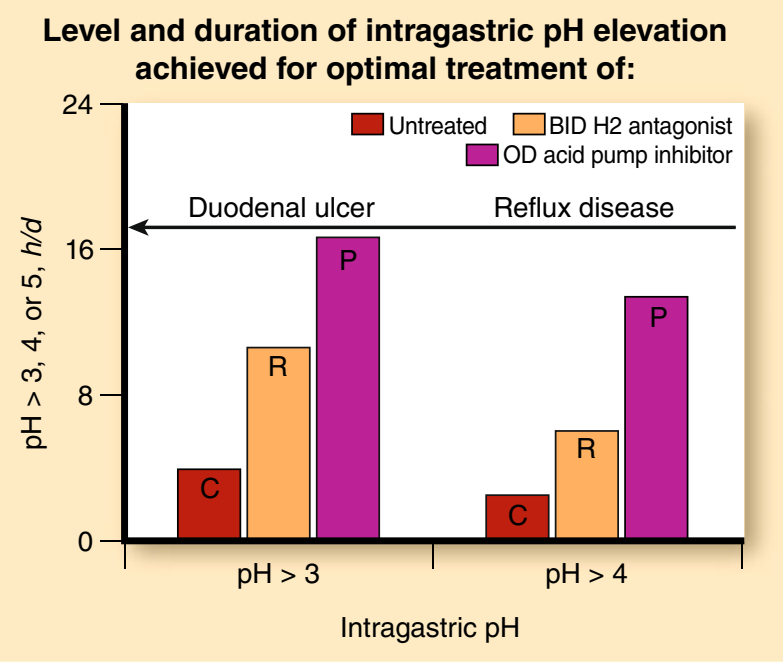

Fig. 3 The results of a meta-analysis defining the degree and duration of intragastric $\mathrm{pH}$ elevation for optimal treatment of duodenal ulcer and gastroesophageal reflux disease and comparing the effect of ranitidine and omeprazole. BID - twice daily; OD — once daily

Esomeprazole is now generally viewed as the PPI of choice for treatment of GERD.

However, as is evident from the $\mathrm{pH}$ profile, even with esomeprazole, $40 \mathrm{mg}$, acidity at night drops to $\mathrm{pH} 3$ or less for several hours. Clearly, this condition will result in continuing damage and symptoms. The improvement in intragastric $\mathrm{pH}$ with esomeprazole, $40 \mathrm{mg}$, can be ascribed to the small extension of plasma residence allowing more pumps to be inhibited. Even administering a PPI twice a day does not ablate nighttime acid secretion. With oncedaily administration, about $70 \%$ of the pumps are inhibited, and with twice-daily adminstration, $80 \%$ are inhibited, still leaving $20 \%$ active pumps at steady state. Also, at night intragastric $\mathrm{pH}$ is not buffered by food, so that $\mathrm{pH}$ drops to about 1.0 in the absence of medication and to less than 3.0, even with adminstration of esomeprazole, $40 \mathrm{mg}$.

In the past decade or so, it has become evident that these drugs have not provided the optimum treatment for acidrelated diseases and that a new target has to be achieved, namely a $\mathrm{pH}$ of 5.0 or above for close to $24 \mathrm{~h}$ per day, but also with no excursion to intragastric $\mathrm{pH}$ less than 3.0.

\section{Pharmacologic Considerations}

Despite their undoubted success in clinical management of patients with acid-related disorders, the currently approved PPIs have several limitations that stem from their pharmacokinetics and mechanism of action. The effectiveness of the initial antisecretory action of a PPI depends on the dose and timing in relation to meals, the plasma half-life of the PPI, and the state of activation of the parietal cell. The 


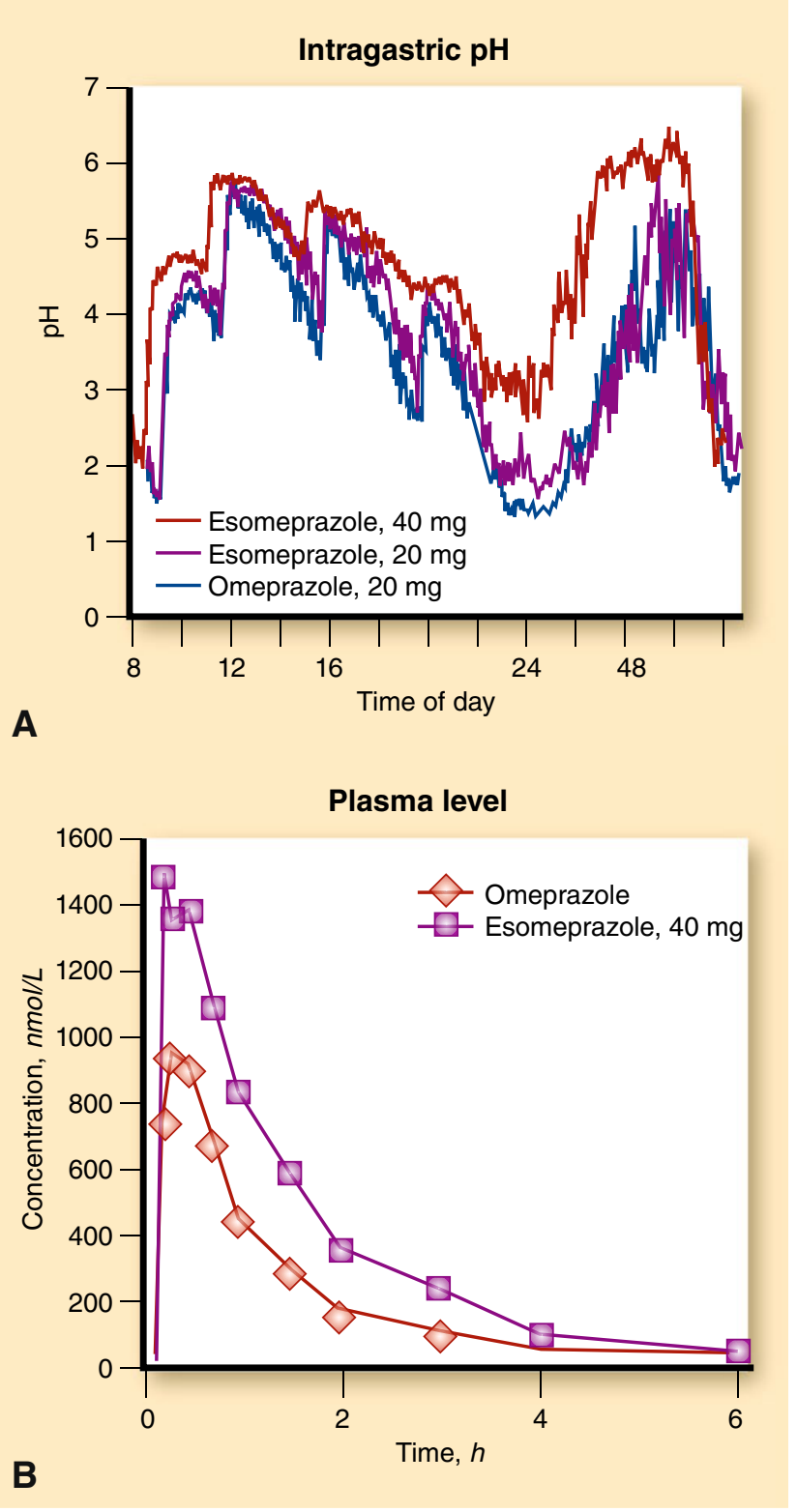

Fig. 4 A comparison of the effect of omeprazole and esomeprazole on a intragastric $\mathrm{pH}$ after 5 days of treatment and $\mathbf{b}$ plasma residence time

currently available gastroprotected PPIs should be taken $30 \mathrm{~min}$ to $1 \mathrm{~h}$ before the first meal of the day, to ensure that the proton pumps (H, K-ATPase) are maximally activated in the parietal cell when the drug is available in the plasma.

\section{Clinical Implications}

Because the PPIs all have similar plasma half-lives of 1 to $2 \mathrm{~h}$, any proton pumps that are synthesized after the plasma level of the PPI falls below the relative threshold of $50 \mathrm{ng} /$ $\mathrm{mL}$ will not be blocked from secreting acid. All current PPIs are short-acting drugs, which cannot control acid secretion over the entire 24-hour period with a single dose. It has been suggested that $30 \%$ of patients require twicedaily dosing to obtain effective control of daytime and nighttime symptoms [4]. A significant proportion of patients being prescribed PPIs are not given the appropriate advice and dosing instructions. In a study of 1046 US primary care doctors, $36 \%$ did not give their patients advice on when and how to take their medication [5]. Moreover, in a survey of 173 patients with GERD taking delayed-release PPI treatment, only $27 \%$ took their PPI correctly (up to 60 min before any meal of the day) and only $9.7 \%$ dosed optimally (15-60 min before the first meal of the day) [6]. A PPI that could be administered independently of meals would be likely to improve compliance and acceptability for many patients.

\section{Unmet Clinical Needs in the Patient with Acid-Related Disorders}

Thus, unmet clinical needs exist despite the apparent benefits of currently approved delayed-release PPIs. Such needs include serious challenges in GERD, several of which are addressed here, and NERD, which is touched on by implication. Space does not permit discussion of other important areas, which include the need for improved acid control for upper GI bleeding, nonvariceal and variceal upper GI bleeding, and management and prevention of stress-related mucosal damage in intravenous and oral formulations [7]. Other important areas include the treatment and prevention of NSAID-related upper GI injury, which is acid-dependent. NSAIDs are usually given two or more times per day, and a once-daily PPI does not adequately control acid later in the day and at night (see below) [8]. Similar arguments exist for the combination therapy of PPIs with antibiotics for the optimal eradication of $H$. pylori infection.

\section{Unmet Needs in the Patient with GERD}

A recent cross-sectional survey of 726 patients on longterm PPIs (39\% GERD) found that reflux symptoms persisted in $59 \%$ of patients [9॰]. Our recent meta-analysis of symptomatic GERD patients found that in about two thirds of patients, reflux symptoms are not adequately controlled after the first dose of a PPI, and nearly $50 \%$ of patients still suffer symptoms 3 days later [10].

Erosive esophagitis healing is one important trial endpoint, and a substantial proportion of patients do not heal after standard doses of PPIs for 8 weeks. The weighted healing rate for all grades of erosive esophagitis for five marketed PPIs at standard doses for 8 weeks ranges from 
$81 \%$ (omeprazole, $20 \mathrm{mg}$, once in the morning) to $86 \%$ (esomeprazole, $40 \mathrm{mg}$, once in the morning) in published clinical trials (our McMaster University database on file). Nonresponse of erosive esophagitis increases with severity of erosive esophagitis grading. The healing rate for Los Angeles grade $\mathrm{C}$ and grade $\mathrm{D}$ erosive esophagitis on standard doses of PPIs suggests that about $40 \%$ of moderate (grade C) and $51 \%$ of severe (grade D) erosive esophagitis were not healed after 4 weeks, and $18 \%$ of grade $\mathrm{C}$ and $27 \%$ of grade D were not healed at 8 weeks [11]. An intragastric $\mathrm{pH}$ of at least 4.0 maintained for $16 \mathrm{~h}$ is generally considered the target to promote healing of erosive esophagitis with antisecretory drugs [12]. Limited published data show that in healthy volunteers, the time that $\mathrm{pH}$ is less than 3 ranges from $27.8 \%$ to $44.1 \%$ during the 24-hour period and $36.1 \%$ to $65.7 \%$ for the nighttime, on standard doses of PPI after 5 to 8 days [13]. Nonhealing rates of erosive esophagitis were $26.8 \%$ to $34.6 \%$ at 4 weeks and $14.4 \%$ to $19.5 \%$ at 8 weeks. Any increase in the time the $\mathrm{pH}$ is below 3 in $24 \mathrm{~h}$ is associated with an increase in the proportion of unhealed erosive esophagitis at 8 weeks. Therefore, the intragastric $\mathrm{pH}$ holding time less than 3 might be a suitable predictor for erosive esophagitis nonhealing; prospective studies are needed [13]. The time $\mathrm{pH}$ is equal to or less than 2 may also predict nonhealing. In a recent post-hoc analysis of two of our pharmacodynamic trials, we found that $19 \%$ of the 24 -hour and $40 \%$ of the midnight to 0700 periods intragastric $\mathrm{pH}$ was 2 or less after esomeprazole, $40 \mathrm{mg}$, once in the morning for 7 days [14].

Moreover, giving double-dose PPI does not completely inhibit gastric acid secretion and relieve all persisting reflux symptoms in patients on PPI. In one report, $16 \%$ of patients had pathologic esophageal $\mathrm{pH}$ monitoring despite doubledose PPI; however, the authors did not define whether double-dose referred to twice-daily administration [15]. Although PPIs are commonly given twice daily to patients not responding to once-daily PPI or to those with nocturnal symptoms, little is known of intragastric $\mathrm{pH}$ profiles on twice-daily PPIs. Based on our meta-analysis, when standard doses of delayed release-PPIs are given twice daily in healthy volunteers for 5 to 8 days, 24-hour median $\mathrm{pH}$ reaches at least 4.6. However, $\mathrm{pH}$ for up to one third of the nighttime was less than $4(15 \%-36 \%$ of the time) and less than 3 (5\%-28\% of the time). Esomeprazole, $40 \mathrm{mg}$, twice daily in healthy volunteers still resulted in $15 \%$ of the nighttime with intragastric $\mathrm{pH}$ less than 4 [16]. Thus, in patients with reflux, this period of acidification is still some fourfold longer than the Johnson-DeMeester criteria for acid reflux.

Most patients will experience reflux after midnight, when the supine time is associated with more reflux events [17], and even delayed-release PPIs given twice daily may still not control nighttime acidity. About $60 \%$ to $80 \%$ of patients have persistent gastric acidity at night despite twice-daily PPIs [18], and about $25 \%$ of reflux patients fail to respond to a twice-daily PPI for 4 to 8 weeks [19]. No clinical trial has yet compared twice-daily versus once-daily PPI for patients with NERD.

These findings may explain the increasing number of reports indicating that as many as $40 \%$ of patients with GERD are not fully satisfied with their antireflux therapy, and about $20 \%$ require a PPI twice daily in an attempt to control acid secretion in the later part of the day or at night to heal severe esophagitis or relieve symptoms [20]. Similarly, Chey et al. [21] found that a higher proportion of those with nighttime symptoms took prescription PPIs twice daily $(24.3 \%$ vs $12.7 \%, P=0.008)$ and were more likely to supplement their PPIs with other GERD medications (45.5\% vs $27.9 \%, P=0.003$ ).

Sleep difficulty increased with nighttime symptom severity (OR, 3.88 for moderate severity and 13.95 for severe/very severe when compared with those with slight severity). Most GERD patients receiving PPIs report nighttime symptoms, with about half having sleep impairment. The risk of sleep impairment and work loss increases with GERD nighttime symptom severity [21].

A US Gallup survey of 1,000 adults experiencing frequent heartburn found that of the $79 \%$ of responders with nighttime heartburn, $75 \%$ reported disturbed sleep and over-the-counter medications were ": largely ineffective" [22]. Although the precise role of nocturnal acidification is not clear, the relationship emphasizes the importance of pharmacologic nocturnal acid control [23•].

These areas of unmet medical needs highlight where more effective acid suppression would bring benefit to patients. Thus, 24-hour $\mathrm{pH}$ control is suboptimal in about $40 \%$ of patients, leading to continuing symptoms and slow or poor healing in grade C and grade D GERD, frequent dosing is necessary for NSAID protection, and triple therapy is still required for $H$. pylori eradication.

\section{Improving the Design of PPIs: Long-Lasting PPIs and K-Competitive Acid Blockers}

The ideal parietal cell acid-blocking agent would possess either plasma half-life kinetics to permit full 24-hour inhibition of H,K-ATPase or the ability to block H,KATPase in either the inactive or active state. Therefore, we focus on the development of such agents.

\section{Tenatoprazole}

Tenatoprazole is an imidazo-pyridine. This results in a fairly normal primary $\mathrm{pK}_{\mathrm{a}}$ but a marked reduction in secondary $\mathrm{pK}_{\mathrm{a}}$. The rate of activation of this compound to 
the active intermediates is slower than those of omeprazole, lansoprazole, and rabeprazole (Fig. 5) [24]. Slow activation of tenatoprazole enables tenatoprazole binding to Cys822, which is located in the membrane domain, giving truly irreversible inhibition $[25,26]$.

Tenatoprazole has a much slower metabolism than omeprazole, lansoprazole, and rabeprazole, giving a plasma half-life of about $6 \mathrm{~h}$ (Fig. 6). The longer plasma half-life of tenatoprazole, combined with its ability to bind to Cys822, provides longer inhibition of gastric acid secretion.

The patent on the core structure of tenatoprazole was extended by synthesis of the S-enantiomer, with superior pharmacokinetics. Early human studies have shown that administration of tenatoprazole, $40 \mathrm{mg}$, at night provides superior acid control compared to esomeprazole, and better daytime control [27, 28].

\section{Extended Release of PPIs}

Using a formulation technology delaying drug release, a longer duration of effective plasma concentration of the drug dexlansoprazole is the $(\mathrm{R})$-enantiomer of lansoprazole, $(R)-(+)-2-([3-m e t h y l-4-(2,2,2-$ trifluoroethoxy)pyridin-2-yl] methylsulfinyl)-1H-benzo[ $d]$ imidazole. Dexlansoprazole $\mathrm{MR}$ is a novel dual delayed-release formulation of dexlansoprazole approved by the FDA for the treatment of acid-related disorders. Dexlansoprazole MR extends drug exposure and somewhat prolongs $\mathrm{pH}$ control compared with lansoprazole (Fig. 7).
In a pharmacokinetic study of dexlansoprazole MR, the plasma concentration of dexlansoprazole was characterized by two distinct peaks and a prolonged drug exposure during the 24-hour dosing interval. Maximum concentration $\left(\mathrm{C}_{\max }\right)$ was achieved at 4 to $4.5 \mathrm{~h}$ after administration of dexlansoprazole MR. Approximate dose proportionality was observed for mean peak plasma concentration (>100 ng/mL) and area under the plasma-concentration time curve after administration of dexlansoprazole MR.

Doses of dexlansoprazole MR generally produced greater gastric acid suppression than lansoprazole. Based on the exposure-response analysis using combined data from two trials [29], the predicted mean 24-hour intragastric $\mathrm{pH}$ values were 4.06 for the dexlansoprazole MR, 30-mg dose, and 4.35 for the dexlansoprazole MR, 90-mg dose. The percent of time $\mathrm{pH}$ greater than 4 over 24-hour values were $59.2 \%$ for dexlansoprazole MR, $30 \mathrm{mg}$, and $66.7 \%$ for dexlansoprazole MR, $90 \mathrm{mg}$. No appreciable additional gain in the pharmacodynamic response was predicted for dexlansoprazole MR, $120 \mathrm{mg}$, and thus this dose was not approved by the FDA for treatment of GERD [29].

A study of the efficacy and safety of dexlansoprazole MR in healing erosive esophagitis showed better healing rates than lansoprazole [30•]. Dexlansoprazole MR, $90 \mathrm{mg}$, healed $92 \%$ to $95 \%$ of patients in individual studies versus $86 \%$ to $92 \%$ for lansoprazole, using life-table analysis. In an integrated analysis of 8 -week healing in patients with moderate-to-severe erosive esophagitis, dexlansoprazole MR, $90 \mathrm{mg}$, was superior to lansoprazole. All treatments
Fig. 5 Tenatoprazole is a pyridinylmethylsulfinyl imidazopyridine compound, which is a weak base. This compound has three $\mathrm{pK}_{\mathrm{a}} \mathrm{s}$. One is the pyridine $\mathrm{pK}_{\mathrm{a}}$ of pyridinylmethyl moiety and the others are the imidazole $\mathrm{pK}_{\mathrm{a}}$ and the pyridine $\mathrm{pK}_{\mathrm{a}}$ of the imidazopyridine moiety. The pyridine $\mathrm{pK}_{\mathrm{a}} 1$ enables tenatoprazole accumulation in the acidic canaliculus of the parietal cell. Protonation of the imidazopyridine ring enhances electron deficiency at the C-2 position, allowing intramolecular rearrangement to the active form. The active form is the sulfenic acid and/or cyclic sulfonamide, and reacts with luminal cysteine thiols of the enzyme to inhibit the enzyme activity

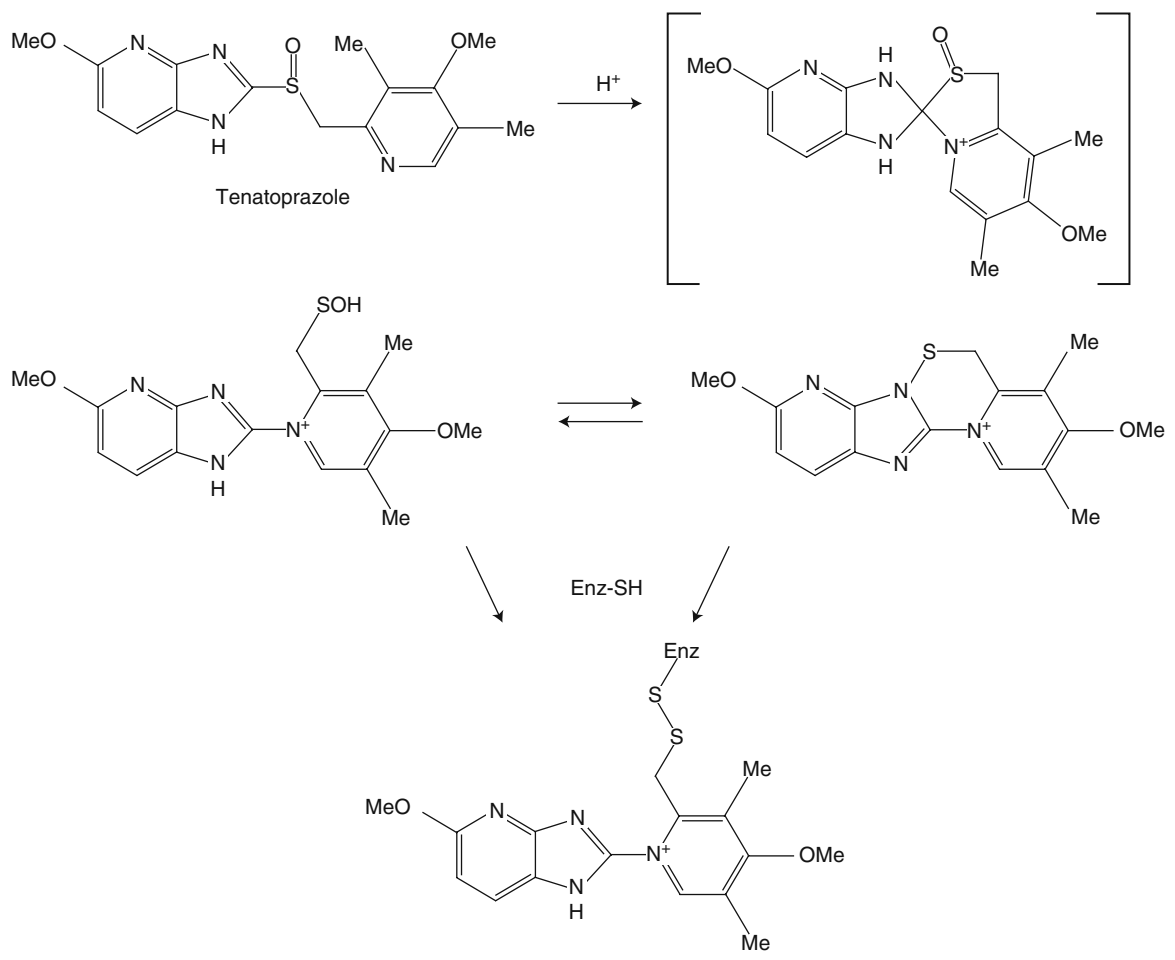


Fig. 6 Profile of the median $\mathrm{pH}$ curves over $48 \mathrm{~h}$ comparing esomeprazole with tenatoprazole. Improvement is seen in $\mathrm{pH}$ control with tenatoprazole, but still with several excursions to $\mathrm{pH}$ $<4.0$. D1 - first day; D2 - second day; E40 mg-esomeprazole, $40 \mathrm{mg}$; T40 mg-tenatoprazole, $40 \mathrm{mg}$. (Data from Galmiche et al. [28].)

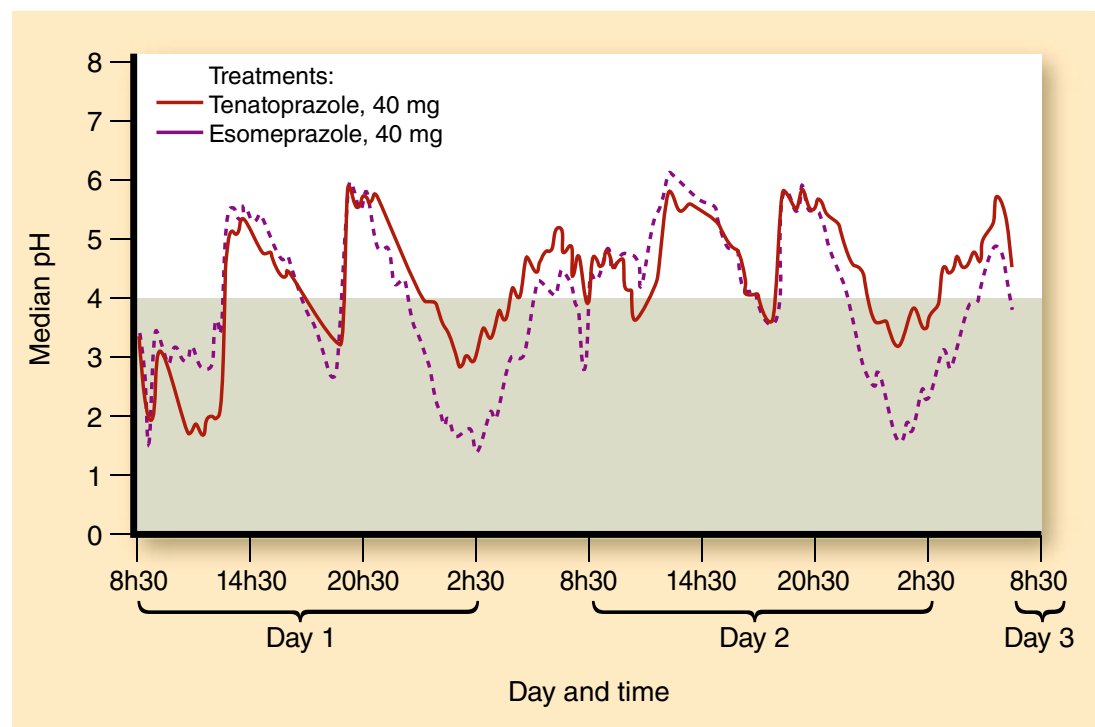

effectively relieved symptoms and were well-tolerated. Dexlansoprazole MR is highly effective in healing erosive esophagitis and offers benefits over lansoprazole, particularly in moderate-to-severe disease [30•]. Another study with a large number of patients confirmed these results

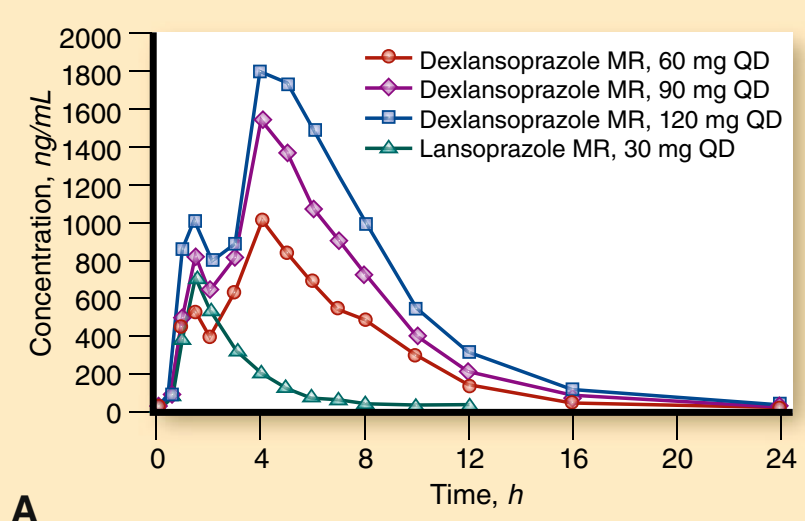

A

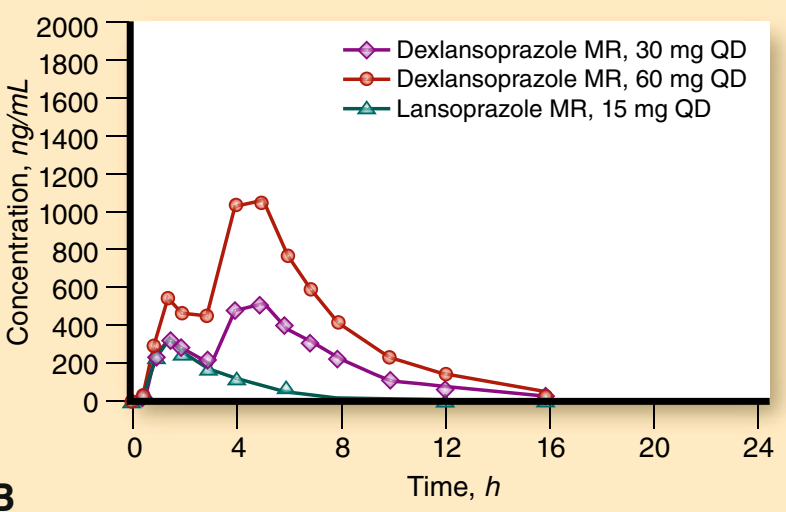

Fig. 7 Mean plasma concentration-time profiles of dexlansoprazole and lansoprazole on day 5 in study 1 a and study 2 b QD — once daily. (Data from Vakily et al. [29].)
[31]. Patients $(N=451)$ with erosive esophagitis that was healed in either of two dexlansoprazole MR healing trials randomly received dexlansoprazole MR, 60 or $90 \mathrm{mg}$, or placebo once daily in this double-blind trial. The percentage of patients who maintained healing at month 6 was analyzed using life-table and crude-rate methods. Secondary endpoints were percentages of nights and of 24-hour days without heartburn based on daily diaries. Maintenance rates were $87 \%$ for the $60-\mathrm{mg}$ dose and $82 \%$ for the 90 -mg dose, versus $26 \%$ for placebo (life table), and $66 \%$ for the $60-\mathrm{mg}$ dose and $65 \%$ for the $90-\mathrm{mg}$ dose, versus $14 \%$ (crude rate). Both doses were superior to placebo for the percentage of 24hour heartburn-free days (60 mg, 96\%; $90 \mathrm{mg}, 94 \%$; placebo, $19 \%$ ) and nights (60 mg, 98\%; $90 \mathrm{mg}, 97 \%$; placebo, 50\%).

\section{Alevium (AGN201904-Z)}

In an effort to develop a PPI that possessed longer plasma dwell time, a novel compound, Alevium (AGN201904-Z; Alevium Pharmaceuticals, Encinitas, CA), was synthesized. This compound is a prodrug form of omeprazole that provides a longer plasma dwell time because, unlike all other PPIs, it is slowly absorbed throughout the small intestine and not just in the duodenum. Of various derivatives tested, a sulfonamide derivative - the phenoxyacetic acid sodium salt derivative of omeprazole - is a candidate drug with several desirable properties. Its structure is shown in Fig. 8.

Because one of the benzimidazole nitrogens is substituted, the compound is acid-stable, unlike any other PPI, and therefore does not require enteric coating. Furthermore, it is neutral $\mathrm{pH}$-stable, thus not requiring alkaline solutions for stability in intravenous formulation, distribution, or administration. It is slowly absorbed throughout the small intestine, but then is rapidly hydrolyzed in the blood to omeprazole and 


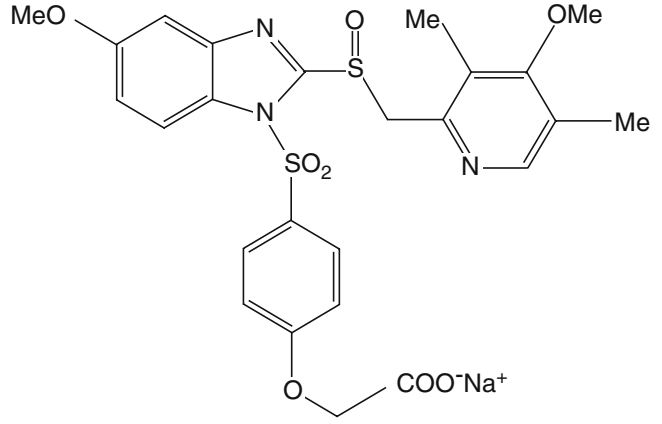

Fig. 8 Chemical structure of Alevium (AGN 201904-Z; Alevium Pharmaceuticals, Encinitas, CA)

the sulfonic acid. Only trace quantities of the intact molecule are ever found in humans, hence its safety profile should resemble that of omeprazole. Figure 9 shows the pharmacokinetic profile in human volunteers following administration of Alevium (AGN201904-Z), $600 \mathrm{mg}$, and illustrates the longer residence time above $50 \mathrm{ng} / \mathrm{mL}$ from Alevium compared to esomeprazole [32•]. Moreover, the longer residence time does not generate a greater $\mathrm{C}_{\max }$, as would be the case with high-dose native PPIs.

Figure 9 shows prolongation of the residence time of omeprazole in the blood, so that drug is present at

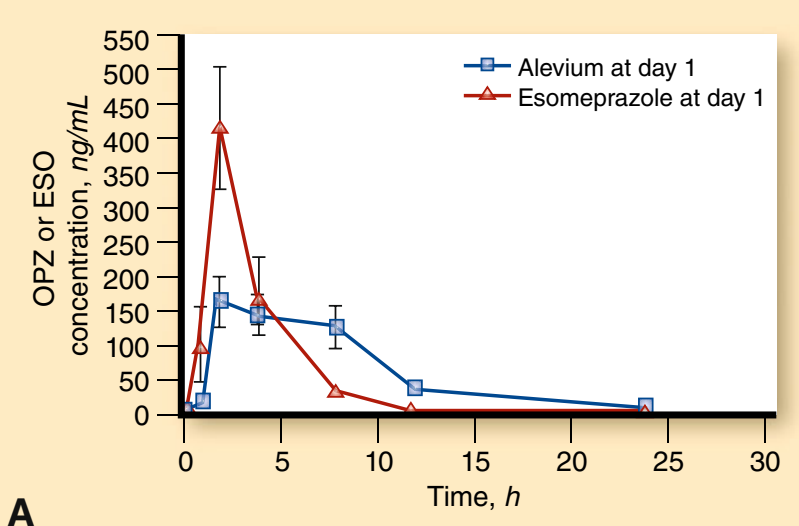

A

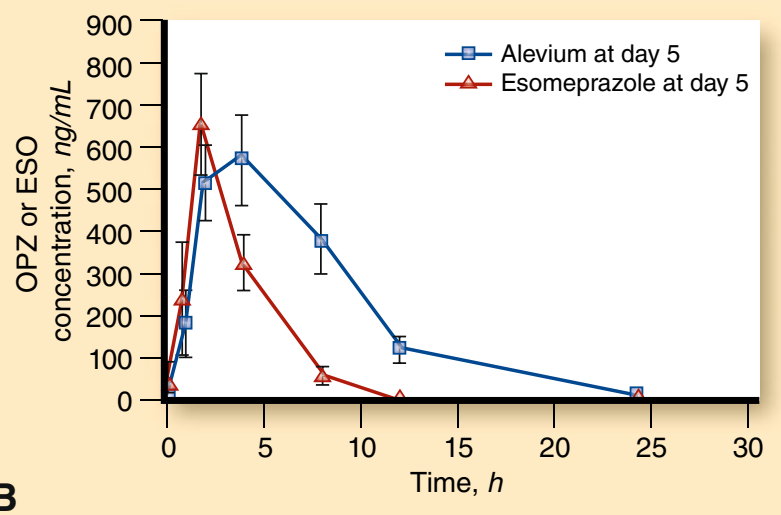

Fig. 9 Mean plasma concentration-time profiles of Alevium (AGN 201904-Z) and esomeprazole from two separate trials evaluating at a day 1 and $\mathbf{b}$ day 5. (Data from Hunt et al. [32•]) inhibitory levels over $24 \mathrm{~h}$ after 5 days administration. This finding leads to considerable improvement in the profile of intragastric pH (Fig. 10).

With once-daily Alevium (AGN201904-Z), the pH is stably maintained at greater than 4.0. Averaging $\mathrm{pH}$ values over $24 \mathrm{~h}$ or at night shows the remarkable advantage of Alevium, not only at night, but also during the day [32•].

\section{Potassium-Competitive Acid Blockers}

Drugs of this class of inhibitor block acid pumping by $\mathrm{K}^{+}$ competitive inhibition, so this class is called either acid pump antagonists or potassium-competitive acid blockers (P-CABs). The first core structure of a P-CAB developed in $1980 \mathrm{~s}$ was an imidazo-pyridine. A typical structure of this class having excellent inhibitory activity is $\mathrm{SCH} 28080$. Later, many P-CABs were developed, some of which are shown in Fig. 11.

Because $\mathrm{P}-\mathrm{CAB}$ inhibits the acid pump enzyme by $\mathrm{K}^{+}$ competition, $\mathrm{P}-\mathrm{CABs}$ do not require acid-activation. Therefore, the inhibition by P-CABs is expected to be fast and effective. Data in humans show rapid and virtually complete inhibition by P-CABs. For example, in healthy volunteers, high doses of the compound AZD0865 resulted in more than 95\% inhibition of acid secretion within $1 \mathrm{~h}$ after oral administration [33]. This inhibitor exhibits a classical (sigmoid) dose-response profile, with the magnitude and duration of effect determined by dose, $\mathrm{pK}_{\mathrm{a}}$, and plasma half-life. AZD0865 demonstrated a doseeffect relationship with a dose-dependent duration of inhibition of acid secretion; more than $95 \%$ inhibition was sustained for up to $15 \mathrm{~h}$ for 0.8 and $1 \mathrm{mg} / \mathrm{kg}$ doses [33]. Surprisingly, even though AZD0865 provided a faster onset of acid inhibition with a dose-dependent duration of activity, a clinical study using once-daily administration showed no clinical benefit over esomeprazole [34, 35$]$. In a study of a randomized, comparative trial of AZD0865 and esomeprazole for the treatment of patients with NERD, using a total of 1469 patients, AZD0865 did not provide clinical benefit over esomeprazole, $20 \mathrm{mg}$, in the management of patients with NERD [34•]. However, increasing the frequency of administration of AZD0865 to twice daily would be expected to outperform currently approved PPIs. Of particular relevance is the finding that about $20 \%$ of patients continue to experience symptoms even with twice-daily administration of any PPI. This finding is largely the result of de novo pump synthesis occurring after the drug has dropped below threshold in the blood, about 90 min after administration. A P-CAB with a long half-life would still be present and more effective than a PPI.

A fused-ring system is soraprazan. Soraprazan inhibited H,K-ATPase with $\mathrm{IC}_{50}$ of $0.1 \mu \mathrm{M}, \mathrm{K}_{\mathrm{i}}$ of $6.4 \mathrm{nM}$, and $\mathrm{K}_{\mathrm{d}}$ of $26.4 \mathrm{nM}$ [36]. However, no detailed clinical data are available for this compound. 
Fig. 10 Comparison of median 24-hour $\mathrm{pH}$ profiles on day 5 for Alevium (AGN 201904-Z; $N=11)$ and esomeprazole $(N=12)$
Median $\mathrm{pH}$ profiles of 23 subjects on day 5 , Alevium $(N=11)$ vs Esomeprazole $(N=12)$

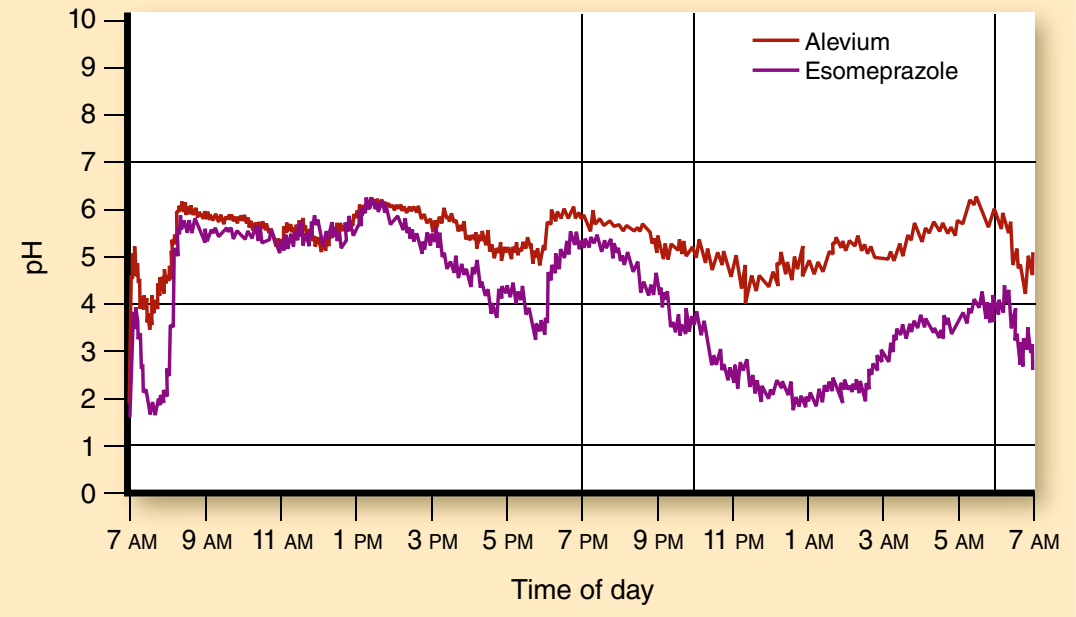

A new type of P-CAB is being developed by Takeda Pharmaceuticals (Osaka, Japan) [37]. One of the typical structures is shown in Fig. 9. Some of these (hetero) arysulfonylpyrrole compounds showed an $\mathrm{IC}_{50}$ value of 9 to $30 \mathrm{nM}$. Among them, TAK-438 has been extensively studied. In rats, TAK- 438 at a dose of $4 \mathrm{mg} / \mathrm{kg}$, orally, completely inhibited gastric acid secretion, giving a higher $\mathrm{pH}$ of gastric perfusate than did SCH28080. Also, the inhibition by TAK-438 was sustained longer than either lansoprazole or SCH28080 [38]. This compound is still in phase 2 trials.

\section{Conclusions}

Despite the overall effectiveness of the current PPIs, many important clinical needs remain unmet, with more than $20 \%$ of patients with GERD experiencing recalcitrant symptoms, even when taking their drug twice daily. This finding is essentially a result of the short plasma residence time and lack of effect during the later part of the day and especially at night, which cannot be overcome by increasing the dose or frequency. Although the unmet clinical needs are discussed here for GERD, the unmet needs are similar for
Fig. 11 Chemical structures of some potassium-competitive acid blockers<smiles>Cc1nc2c(OCc3ccccc3)cccn2c1C=N</smiles>

$\mathrm{SCH} 28080$<smiles>COCCOC1c2ccn3c(C)c(C)nc3c2NC(c2ccccc2)C1O</smiles>

Soraprazan<smiles>Cc1cccc(C)c1CNc1cc(C(=O)NCCO)cn2c(C)c(C)nc12</smiles>

AZD0865<smiles>CNCc1cc(-c2ccccc2F)n(S(=O)(=O)c2cccnc2)c1</smiles>

TAK-438 
the optimal management of nonvariceal upper GI bleeding, NSAID gastropathy, and $H$. pylori eradication, and emanate from the same pharmacologic shortcomings described in this review.

Disclosure No potential conflict of interest relevant to this article was reported.

Open Access This article is distributed under the terms of the Creative Commons Attribution Noncommercial License which permits any noncommercial use, distribution, and reproduction in any medium, provided the original author(s) and source are credited.

\section{References}

Papers of particular interest, published recently, have been highlighted as:

- Of importance

1. Chiba N, De Gara CJ, Wilkinson JM, Hunt RH: Speed of healing and symptom relief in grade II to IV gastroesophageal reflux disease: a meta-analysis. Gastroenterology 1997, 112:1798-1810.

2. Teyssen S, Chari ST, Scheid J, Singer MV: Effect of repeated boluses of intravenous omeprazole and primed infusions of ranitidine on 24-hour intragastric $\mathrm{pH}$ in healthy human subjects. Dig Dis Sci 1995, 40:247-255.

3. Gedda K, Scott D, Besancon M, et al.: Turnover of the gastric H+, $\mathrm{K}(+)$-adenosine triphosphatase alpha subunit and its effect on inhibition of rat gastric acid secretion. Gastroenterology 1995, 109:1134-1141.

4. Fass R, Shapiro M, Dekel R, Sewell J: Systematic review: proton-pump inhibitor failure in gastro-oesophageal reflux disease-where next? Aliment Pharmacol Ther 2005, 22:79-94.

5. Chey WD, Inadomi JM, Booher AM, et al.: Primary-care physicians' perceptions and practices on the management of GERD: results of a national survey. Am J Gastroenterol 2005, 100:1237-1242.

6. Pezanoski J, Guanaratnam N, Cowen M: Correct and incorrect dosing of proton pump inhibitors and its impact on GERD symptoms. Gastroenterology 2003, 124(Suppl 1):A228.

7. Hunt RH: Review article: the unmet needs in delayed-release proton-pump inhibitor therapy in 2005. Aliment Pharmacol Ther 2005, 22(Suppl 3):10-19.

8. Scarpignato C, Hunt RH: Non-steroidal anti-inflammatory drug related injury of the gastrointestinal tract: clinical picture pathogenesis and prevention. Gastroenterol Clin North Am 2010 , in press.

9. - Raghunath AS, Hungin AP, Mason J, Jackson W: Symptoms in patients on long-term proton pump inhibitors: prevalence and predictors. Aliment Pharmacol Ther 2009, 29:431-439. Patients often suffer ongoing moderate or severe symptoms when on long-term treatment. GERD and uninvestigated dyspepsia were associated with poor long-term symptom control.

10. Yuan Y, Wang CC, Yuan Y, Hunt RH: The proportion of patients who are free of reflux symptoms during the initial days of treatment with proton pump inhibitors (PPIs) in GERD trials: a meta-analysis. Gastroenterology 2008; 134(4, Suppl 1):A174. Abstract S1085.

11. Yuan Y, Vinh B, Hunt RH: Nonhealed rate of moderate-severe (LA Classification Grade C and D) erosive esophagitis after 48 weeks proton pump inhibitors (PPIs): evidence of an unmet need. Gastroenterology 2009, 136(Suppl):A440.
12. Hunt RH: Importance of $\mathrm{pH}$ control in the management of GERD. Arch Intern Med 1999, 159:649-657.

13. Yuan $\mathrm{Y}$, Hunt $\mathrm{RH}$ : Intragastric $\mathrm{pH}$ holding time $\mathrm{pH}<3$ at steady state in healthy volunteers (HV) after once daily PPIs: a predictor for low erosive esophagitis (EE) healing rates? Gastroenterology 2009, 136(Suppl):M1990.

14. Wang CC, Yuan Y, Chen Y, Hunt RH: Night-time $\mathrm{pH}$ holding time: what is hidden by the $\%$ of time $\mathrm{pH} \geq 4$ ? Am J Gastroenterol 2008, 103(Suppl 1):S51.

15. Karamanolis G, Vanuytsel T, Sifrim D, et al.: Yield of 24-hour esophageal $\mathrm{pH}$ and bilitec monitoring in patients with persisting symptoms on PPI therapy. Dig Dis Sci 2008, 53:2387-2393.

16. Yuan Y, Hunt RH: Intragastric acid suppressing effect of proton pump inhibitors twice daily at steady state in healthy volunteers: evidence of an unmet need? Am J Gastroenterol 2008, 103(Suppl):S50.

17. Orr WC: Reflux events and sleep: are we vulnerable? Curr Gastroenterol Rep 2006, 8:202-207.

18. Richter JE: The patient with refractory gastroesophageal reflux disease. Dis Esophagus 2006, 19:443-447.

19. Richter JE: How to manage refractory GERD. Nat Clin Pract Gastroenterol Hepatol 2007, 4:658-664.

20. Katz PO, Castell DO, Chen Y, et al.: Intragastric acid suppression and pharmacokinetics of twice-daily esomeprazole: a randomized, three-way crossover study. Aliment Pharmacol Ther 2004, 20:399-406.

21. Chey WD, Mody R, Chen L, et al.: Nighttime symptoms and sleep impairment among patients with gastro-esophageal reflux disease (GERD) receiving prescription ( $\mathrm{Rx})$ proton pump inhibitors (PPIs). Gastroenterology 2008, 134(4 Suppl 1): A323-A324.

22. Shaker R, Castell DO, Schoenfeld PS, Spechler SJ: Nighttime heartburn is an under-appreciated clinical problem that impacts sleep and daytime function: the results of a Gallup survey conducted on behalf of the American Gastroenterological Association. Am J Gastroenterol: 2003, 98:1487-1493.

23. - Yuan Y, Hunt RH Evolving issues in the management of reflux disease? Curr Opin Gastroenterol 2009, 25:342-351. Although GERD is common, management still poses many challenges, which are addressed in this paper together with the unmet needs in reflux disease.

24. Shin JM, Cho YM, Sachs G: Chemistry of covalent inhibition of the gastric $(\mathrm{H}+, \mathrm{K}+)$-ATPase by proton pump inhibitors. J Am Chem Soc 2004, 126:7800-7811.

25. Shin JM, Homerin M, Domagala F, Ficheux H, Sachs G: Characterization of the inhibitory activity of tenatoprazole on the gastric $\mathrm{H}+, \mathrm{K}+$-ATPase in vitro and in vivo. Biochem Pharmacol 2006, 71:837-849.

26. Shin JM, Sachs G: Differences in binding properties of two proton pump inhibitors on the gastric $\mathrm{H}+, \mathrm{K}+$-ATPase in vivo. Biochem Pharmacol 2004, 68:2117-2127.

27. Galmiche JP, Bruley Des Varannes S, Ducrotté P, et al.: Tenatoprazole, a novel proton pump inhibitor with a prolonged plasma half-life: effects on intragastric $\mathrm{pH}$ and comparison with esomeprazole in healthy volunteers. Aliment Pharmacol Ther 2004, 19:655-662.

28. Galmiche JP, Sacher-Huvelin S, Bruley des Varannes S, et al.: A comparative study of the early effects of tenatoprazole $40 \mathrm{mg}$ and esomeprazole $40 \mathrm{mg}$ on intragastric $\mathrm{pH}$ in healthy volunteers. Aliment Pharmacol Ther 2005, 21:575-582.

29. Vakily M, Zhang W, Wu J, et al.: Pharmacokinetics and pharmacodynamics of a known active PPI with a novel Dual Delayed Release technology, dexlansoprazole MR: a combined analysis of randomized controlled clinical trials. Curr Med Res Opin 2009, 25:627-638.

30. - Sharma P, Shaheen NJ, Perez MC, et al.: Clinical trials: healing of erosive oesophagitis with dexlansoprazole MR, a proton pump 
inhibitor with a novel dual delayed-release formulation-results from two randomized controlled studies. Aliment Pharmacol Ther 2009, 29:731-741. This study showed that dexlansoprazole MR is highly effective in healing erosive esophagitis and offers benefits over lansoprazole, particularly in moderate-to-severe disease.

31. Howden CW, Larsen LM, Perez MC, et al.: Clinical trial: efficacy and safety of dexlansoprazole MR 60 and $90 \mathrm{mg}$ in healed erosive oesophagitis - maintenance of healing and symptom relief. Aliment Pharmacol Ther 2009, 30:895-907.

32. - Hunt RH, Armstrong D, Yaghoobi M, et al.: Predictable prolonged suppression of gastric acidity with a novel proton pump inhibitor, AGN 201904-Z. Aliment Pharmacol Ther 2008, 28:187-199. This study showed that a PPI prodrug, AGN201904$Z$, provided superior acid control over esoemprazole. Longer duration of the effective plasma concentration of drug was achieved by slow absorption of the prodrug.

33. Nilsson C, Albrektson E, Rydholm H, et al.: Tolerability, pharmacokinetics and effects on gastric acid secretion after single oral doses of the potassium-competitive acid blocker AZD0865 in healthy male subjects. Gastroenterology 2005, 128(4 Suppl 2):A528.
34. - Dent J, Kahrilas PJ, Hatlebakk J, et al.: A randomized, comparative trial of a potassium-competitive acid blocker (AZD0865) and esomeprazole for the treatment of patients with nonerosive reflux disease. Am J Gastroenterol 2008, 103:20-26. This article provides a comparison of a short acting $K$ competitive inhibitor of the H,K-ATPase with a PPI.

35. Kahrilas PJ, Dent J, Lauritsen K, et al.: A randomized, comparative study of three doses of AZD0865 and esomeprazole for healing of reflux esophagitis. Clin Gastroenterol Hepatol 2007, 5:1385-1391.

36. Simon WA, Herrmann M, Klein T, et al.: Soraprazan: setting new standards in inhibition of gastric acid secretion. J Pharmacol Exp Ther 2007, 321:866-874.

37. Kajino M, Nishida H, Arikawa Y, Hirase K, Ono K, inventors; Takeda Pharmaceutical Company, assignee. Pyrrole compounds. Japanese patent WO 2008/108380 A2. September 12, 2008.

38. Hori Y, Imanishi A, Matsukawa J, et al.: 1-[5-(2-Fluorophenyl)-1(pyridin-3-ylsulfonyl)-1 H-pyrrol-3-yl]-N-methylmet hanamine monofumarate (TAK-438), a novel and potent potassiumcompetitive acid blocker for the treatment of acid-related diseases. J Pharmacol Exp Ther 2010 (Epub ahead of print). 